\title{
The Analysis of Simultaneous Multi-Equations Model on the Relationship between Trade and Economic Growth in China
}

\author{
Huan Chen \\ School of International Business, Southwest University of Finance and Economics \\ Jinsha 2, Room 530, Southwest University of Finance and Economics \\ NO.55, Guanghuacun Street, Qingyang District, Chengdu 610074, China \\ E-mail: chenhuan_369@126.com
}

\begin{abstract}
Since reform and opening up, foreign trade has played an important role in promoting the development of China's market economy. The thesis based on the theory of econometrics makes analysis of simultaneous multi-equations model on the relationship between foreign trade and economic growth in China by the data of 1978-2007, and concludes that export indeed played an important role in promoting economic growth, and the positive effect of export exceeds the negative effect of import; the negative effect of import on the economy can be offset through affecting consumption which impacts on economic growth positively; China's economy will have more space for development because of the discover in the thesis that domestic demand has almost the same effect in promoting economy as export.

Keywords: Lagging effect, Endogenous variable, Predetermined variables

China's foreign trade has developed rapidly since the reform and opening up policy with $13.4 \%$ of an average annual growth rate. This growth rate is leading the world average, and china has caught up with and even surpassed the major developed countries in terms of scales gradually. At the same time, China's economic development has shown impressive results with $9 \%$ of an average annual growth rate. Realistically, Chinese trade promotion strategy for the development has become a model for economic development to a number of countries in the world. Therefore, researching the relationship between China's foreign trade and economic growth has strong practical significance.
\end{abstract}

\section{Introduction}

Over the past years, whether or not china's foreign trade promoting economic growth has been the focus of debate in economic area. As a result of different research methods, economists have different conclusions on this question. Chen Jiaqin (1999) said that the import plays a more important role in promoting the economic growth than export by making use of the methods of Elastic Analysis and Causal Analysis; Shen Chengxiang (1999) used the methods of Causal Test, ADF Unit Root Test and Cointegration Test, and found that there is a reversible causal relationship between export and economic growth but no long-term stable relations in China; Song Shaohua, Song Hongming (2001) made use of the methods of Causal Test, ADF Test and concluded that export promotes the economic growth in the short term, but it is invisible in the long term; Bao Qun, Xu Helian and Lai Mingyong (2003) recognized that different ways will lead to different conclusions and only the degree of dependence on foreign trade can reflect the relationship between economic growth and trade openness better than other variables by Correlation Analysis, Regression Analysis, Variable Regression Model. After further study, they found that economic growth depends mainly on the input of elements but not the trade openness.

So many scholars above used different methods to prove their own point of view, but the author think that the study of the following issues are worth considering:

1.1 More scholars in the study of this issue, only considered the impact of import or export separately on the economy, but did not take full account of the impact of the two variables, the export and import, on economic growth together.

1.2 Previous studies only considered the impact of two variables, export and import, on economic growth without considering other variables, such as investment, consumption, government expenditure, and so on so forth.

1.3 The studies above rarely noticed the lagging effect of the variables and only paid attention to the impact of the current variables on economy.

\section{Model Specifications}

We should consider some aspects researching the relations between foreign trade and economic growth as following: 2.1 The measure of foreign trade

To this point, many economists at home and abroad used to make import or export or their difference as the measure of 
foreign trade. However, it is not comprehensive to consider these indicators separately due to import and export constituting one country's foreign trade together. Therefore, we should take into account the import and export at the same time while researching the impact of foreign trade on economic growth.

\subsection{The measure of economic growth}

There are many indicators to measure a country's economic growth, such as GDP, GNP and economic growth rate, and so on. Which one is more appropriate? The author decided to use GDP as the explained variable to measure economic growth because that the major countries in the world today are using GDP to measure their nations' economic growth, and GNP is lack of time series data relative to GDP.

\subsection{The analysis of the factors}

In this study, the total amount of exports and imports are considered to be the main factors. In addition, there are many other factors that affect economic growth according to economic theories.

First of all, the consumption has played a significant role in economic growth, and Keynesian theory of consumption recognized that consumption can promote the production.

Secondly, in the early period of classical economics, Adam Smith proposed a theory that the capital (investment) is the motivation of the economic growth. So, investment should be considered into the model.

Finally, the Keynesian multiplier theory said that the government's spending could increase national income in number of times, so government spending should also be taken into account as the factors of the model. Therefore, this thesis makes "Import", "Export", "Consumer", "Investment" and "Government Expenditure" as explanatory variables of the model.

\subsection{The design of the model's form}

In this thesis, the theoretic gist of the model's design is based on the Keynesian National Income Accounting Identity: GDP $=$ Consumption + Investment + Government Spending + Exports -Imports, but only a single equation model to explore the relationship between foreign trade and economic growth is not enough considering the probable two-way causal link existing in the variables. As a result, establishing simultaneous multi-equations model is a more appropriate choice. Here, the author assumed that the national income GDP as $\mathrm{Y}_{\mathrm{t}}$, Consumption as $\mathrm{C}_{\mathrm{t}}$ Investment as $\mathrm{I}_{\mathrm{t}}$, Government Spending as $\mathrm{G}_{\mathrm{t}}$, Exports as $\mathrm{EX}_{\mathrm{t}}$, and Imports as $\mathrm{IM}_{\mathrm{t}}$.

The establishment of simultaneous multi-equations model is as following:

$$
\begin{gathered}
Y_{t}=C_{t}+I_{t}+G_{t}+E X_{t}-I M_{t} \\
C_{t}=\alpha_{0}+\alpha_{1} I_{t}+\alpha_{2} C_{t-1}+v_{1 t} \\
I_{t}=\beta_{0}+\beta_{1} Y_{t}+\beta_{2} I_{t-1}+v_{2 t}
\end{gathered}
$$

Here, $\alpha_{\mathrm{i}}$ and $\beta_{\mathrm{i}}(\mathrm{i}=0,1,2)$ are the unknown parameters, and $v_{1 \mathrm{t}}$ and $v_{2 \mathrm{t}}$ are random disturbances representing the combined effects of those factors which affect the explained variables but not taken into the model. Endogenous variables are $Y_{t}, C_{t}$ and $I_{t}$, and endogenous variable number $M=3$. Predetermined variables are $G_{t}, C_{t-1}$ and $I_{t-1}$, and its number $\mathrm{K}=3$.

Note: the above simultaneous multi-equations accord with the conditions of the Two-Stage Least Squares, and the test is elided.

\section{The collection of data}

In this thesis, the relative data of china in 1978 - 2007 are shown in the following Tables.

\section{Insert Table 1 here}

\section{Model identification}

In the simultaneous equations model, the first step is to judge the model's identification in order to obtain a reasonable estimate of the parameters. According to the simultaneous equations (1), (2), (3), we can conclude their standard forms are:

$$
\begin{aligned}
& 0-C_{t}-I_{t}+Y_{t}-G_{t}-E X_{t}+I_{t}+0 \times C_{t-1}+0 \times I_{t-1}=0 \\
& -\alpha_{0}+C_{t}+0 \times I_{t}+0 \times Y_{t}+0 \times G_{t}+0 \times E X_{t}-\alpha_{1} \times I_{t}-\alpha_{2} \times C_{t-1}+0 \times I_{t-1}=v_{1 t} \\
& -\beta_{0}+0 \times C_{t}+I_{t}-\beta_{1} Y_{t}+0 \times G_{t}+0 \times E X_{t}+0 \times I_{t}+0 \times C_{t-1}-\beta_{2} I_{t-1}=v_{2 t}
\end{aligned}
$$

The matrix $(\mathrm{B}, \Gamma)$ of their Standard forms is:

$(B, \Gamma)=\left(\begin{array}{ccccccccc}0 & -1 & -1 & 1 & -1 & -1 & 1 & 0 & 0 \\ -\alpha_{0} & 1 & 0 & 0 & 0 & 0 & -\alpha_{1}-\alpha_{2} & 0 \\ -\beta_{0} & 0 & 1 & -\beta_{1} & 0 & 0 & 0 & 0 & -\beta_{2}\end{array}\right)$ 
Since the equation (4) is an identity, there is no need to judge its identification. The identification of equation (5) and (6) are as following:

4.1 Identification of the equation (5)

First of all, use the order conditioning to judge. Make the number of endogenous variables as $\mathrm{m}_{5}$, and $\mathrm{m}_{5}=2$; make the number of predetermined variables as $\mathrm{k}_{5}$, and $\mathrm{k}_{5}=1$. We know that $\mathrm{K}-\mathrm{k}_{5}=2$ and $\mathrm{m}_{5}-1=1$, so $\mathrm{K}-\mathrm{k}_{5}>\mathrm{m}_{5}-1$. It showed that equation (5) may be over-identification.

Secondly, use the rank conditioning to judge. We draw the second line and its non-zero coefficient which included serials $1,2,7,8$ in $(\mathrm{B}, \Gamma)$ away and we could get:

$\left(B_{0}, \Gamma_{0}\right)=\left(\begin{array}{ccccc}-1 & 1 & -1 & -1 & 0 \\ 1 & -\beta_{1} & 0 & 0 & -\beta_{2}\end{array}\right)$

It is clear that this matrix can form 9 non-zero second order $(\mathrm{M}-1=2)$ determinants, so we can conclude that equation

(5) is over-identification referring to the judgment of its order conditioning.

\subsection{Identification of the equation (6)}

First of all, use the order conditioning to judge. Make the number of endogenous variables as $\mathrm{m}_{6}$, and $\mathrm{m}_{6}=2$; make the number of predetermined variables as $\mathrm{k}_{6}$, and $\mathrm{k}_{6}=1$. We know that $\mathrm{K}-\mathrm{k}_{6}=2$ and $\mathrm{m}_{6}-1=1$, so $\mathrm{K}-\mathrm{k}_{6}>\mathrm{m}_{6}-1$. It showed that equation (6) may be over-identification.

Secondly, use the rank conditioning to judge. We draw the second line and its non-zero coefficient which included serials 1, 4, 9 in $(B, \Gamma)$ away and we could get:

$\left(\mathrm{B}_{0}, \Gamma_{0}\right)=\left(\begin{array}{ccccc}-1 & -1 & -1 & 1 & 0 \\ 1 & 0 & 0 & -\alpha_{1} & -\alpha_{2}\end{array}\right)$

It is clear that this matrix can form 9 non-zero second order $(\mathrm{M}-1=2)$ determinants, so we can conclude that equation (6) is over-identification referring to the judgment of its order conditioning.

\section{Model Estimation}

From the part 4 we know that the model is over-identification, and it is appropriate to use the Two-Stage Least Squares (TSLS) to estimate the parameters. The estimation of equation (2) is as following:

\section{Insert Table 2 here}

According to the table we conclude the TSLS form of equation (2) is:

$\mathrm{C}_{\mathrm{t}}=1180.809+0.257016 \mathrm{IM}_{\mathrm{t}}+0.880683 \mathrm{C}_{\mathrm{t}-1}$

The estimation of equation (3) is as following:

\section{Insert Table 3 here}

According to the table we conclude the TSLS form of equation (3) is:

$\mathrm{I}_{\mathrm{t}}=224.9145-0.123501 \mathrm{Y}_{\mathrm{t}}+1.516373 \mathrm{I}_{\mathrm{t}-1}$

Then we get the TSLS form of the model is:

$$
\begin{aligned}
& Y_{t}=C_{t}+I_{t}+G_{t}+E X_{t}-I_{t} \\
& C_{t}=1180.809+0.257016 I_{t}+0.880683 C_{t-1} \\
& I_{t}=224.9145-0.123501 Y_{t}+1.516373 I_{t-1}
\end{aligned}
$$

Finally we get this equation from equation (7), (8), (9)

$Y_{t}=1251.1992+0.7839 C_{t-1}+1.3497 I_{t-1}+0.8901 G_{t}+0.8901 E_{t}-0.6613 I_{t}$

\section{Conclusion}

6.1 Export indeed plays an important role in promoting economic growth, and the positive effect of export exceeds the negative effect of import

This proves that, to some extent, import and export impact on economic growth together rather than separately. This also proves that the Keynesian National Income Accounting Identity $Y_{t}=C_{t}+I_{t}+G_{t}+E X_{t}-I_{t}$ is right and the form of $Y_{t}=C_{t}+I_{t}+G_{t}+N X_{t}\left(N X_{t}=E X_{t}-I_{t}\right)$ is wrong because their varying extents of effect. This is to say, import and export impact on economic growth together rather than net export. 


\subsection{We should not ignore the role of export plays}

The export-oriented theory of neo-classical economics found that there is causal effect between export and economic growth in the real economic system. On the one hand, expansion of export helps one country to achieve economies of scale and then promote productivity; on the other hand, expansion of export helps one country to accelerate its technological progress and improve its capital efficiency. From the above analysis we do see the export has strong positive effect on economic growth. However, we also get that import has some certain impact on household consumption which is positive to economy from equation (8). The negative effect of import on the economy can be offset through affecting consumption which impacts on economic growth positively and after that its negative effect will be less. Appropriate import could improve technological progress and productivity, and even some kinds of imported goods serve for export directly, which can affect economic growth through export.

\subsection{We should notice the importance of expanding domestic demand besides import and export}

The past consumption, investment and current government spending play a significant role in economic growth. We can see that these variables have almost the same impact on economy as export from the estimation, and some even more than import. All of these provide more space for china's economic development.

From the estimation, we get a result that investment has a negative effect on economic growth which conflicts with investment theory of economics. However, this thesis focuses on the import, export and economic growth, and ignores to test that result. The failure of this thesis in this respect may be due to the bad multi-collinearity of investment and national income.

\section{References}

Balassa, B. (1978). Exports and economic growth: further evidence. Journal of Development Economics, 5, 181-189.

Dutt, S.D. and D. Ghosh. (1996). The export growth-economic growth nexus: causality analyses. The Journal of Developing Areas, 30, 167-182.

Ghartey. E. E. (1993).Casual Relationship between Exports and Economic Growth: Some Empirical Evidence in Taiwan, Japan and the US. Applied-Economics, (9):1145-1152.

Jordan, Shan, \& Fiona, Sun. (1998). On The Export-led Growth Hypothesis: The Econometric Evidence From China. Applied Economics, 30.

Jung, S. W., \& Marshall. (1985). Exports, Growth and Causality in Developing Countries. Journal of Development Economics, (18):1-12.

Shan, J., \& Sun F. (1998b). On the Export-led Growth Hypothesis: The econometric evidence from China. Applied Economics, 30: 1055-1065.

Shan, J., \& Sun F. (1998a). Export-led Growth Hypothesis for Australia: An Empirical Reinvestigation. Applied Economics Letters, 5:423-428.

Sharma, S. C., \& Dhakal, D. (1994). Causal Analysis between Exports and Economic Growth in Developing Countries. Applied Economics, 26:1145- 1158.

Wei, S. (1995). The open door policy and China's rapid growth: evidence from city-level data, in T. Ito and A.O. Krueger (eds.). Growth Theories in Light of the East Asian Experience, Chicago and London, The University of Chicago Press.

Yaghmaian. B, \& Ghorashi. R. (1995). Export Performance and Economic Development: An Empirical Analysis. The American Economist, 37-45. 
Table 1.

\begin{tabular}{|c|c|c|c|c|c|c|}
\hline Year & $\mathrm{Y}_{\mathrm{t}}$ & $\mathrm{C}_{\mathrm{t}}$ & $\mathrm{I}_{\mathrm{t}}$ & $\mathrm{G}_{\mathrm{t}}$ & $\mathrm{EX}_{\mathrm{t}}$ & $\mathrm{IM}_{\mathrm{t}}$ \\
\hline 1978 & 3605.6 & 2239.1 & 1377.9 & 480 & 995.486 & 1113.09 \\
\hline 1979 & 4074 & 2619.4 & 1474.2 & 614 & 1361.41 & 1562.06 \\
\hline 1980 & 4551.3 & 2976.1 & 1590 & 659 & 1809.93 & 1994.13 \\
\hline 1981 & 4901.4 & 3309.1 & 1581 & 705 & 2200.7 & 2201.5 \\
\hline 1982 & 5489.2 & 3637.9 & 1760.2 & 770 & 2232.1 & 1928.5 \\
\hline 1983 & 6076.3 & 4020.5 & 2005 & 838 & 2222.6 & 2139 \\
\hline 1984 & 7164.4 & 4694.5 & 2468.6 & 1020 & 2613.9 & 2741 \\
\hline 1985 & 8792.1 & 5773 & 3386 & 1184 & 2735 & 4225.2 \\
\hline 1986 & 10132.8 & 6542 & 3846 & 1367 & 3094.2 & 4290.4 \\
\hline 1987 & 11784.7 & 7451.2 & 4322 & 1490 & 3943.7 & 4321.6 \\
\hline 1988 & 14704 & 9360.1 & 5495 & 1727 & 4751.6 & 5526.8 \\
\hline 1989 & 16466 & 10556.5 & 6095 & 2033 & 5253.8 & 5914 \\
\hline 1990 & 18319.5 & 11365.2 & 6444 & 2252 & 6209.1 & 53334.5 \\
\hline 1991 & 21280.4 & 13145.9 & 7517 & 2830 & 7191 & 6379.1 \\
\hline 1992 & 25863.7 & 15952.1 & 9636 & 3492.3 & 8494 & 8058.5 \\
\hline 1993 & 34500.7 & 20182.1 & 14998 & 4499.7 & 9174.4 & 10395.9 \\
\hline 1994 & 46690.7 & 26796 & 19260.6 & 5986.2 & 12100.6 & 11561.4 \\
\hline 1995 & 58510.5 & 33635 & 23877 & 6690.5 & 14878 & 13208.4 \\
\hline 1996 & 68330.4 & 40003.9 & 26867.2 & 7851.6 & 15104.8 & 13883.3 \\
\hline 1997 & 74894.2 & 43579.4 & 28457.6 & 8724.8 & 18279.2 & 14237 \\
\hline 1998 & 79003.3 & 46405.9 & 29545.9 & 9484.8 & 18371.2 & 14023.7 \\
\hline 1999 & 82673.1 & 49722.7 & 30701.6 & 10388.3 & 19493.1 & 16569.9 \\
\hline 2000 & 89340.9 & 54600.9 & 32499.8 & 11705.3 & 24920.3 & 22509.4 \\
\hline 2001 & 98592.9 & 58927.4 & 37460.8 & 13029.3 & 26609.8 & 24355.3 \\
\hline 2002 & 107897.6 & 62798.5 & 42304.9 & 13916.9 & 32559.1 & 29517.1 \\
\hline 2003 & 121511.4 & 67442.5 & 51382.7 & 14764 & 43789.9 & 41306.2 \\
\hline 2004 & 124969.5 & 53950 & 70073 & 16445.2 & 59343.9 & 56068.3 \\
\hline 2005 & 168102 & 67177 & 88604 & 26012.1 & 76206.8 & 66015.9 \\
\hline 2006 & 193269.1 & 76410 & 109870 & 30292.7 & 77594.6 & 63376.9 \\
\hline 2007 & 224881 & 89210 & 137239 & 36737.6 & 92787.73 & 77346.48 \\
\hline
\end{tabular}

Source: Statistical Yearbook of China

http://www.stats.gov.cn/tjsj/ndsj/

Note: The units of $Y_{t}, C_{t}, I_{t}, G_{t}, E_{t}$ and $I_{t}$ are 100,000,000 Yuan 
Table 2.

\begin{tabular}{|c|c|c|c|c|}
\hline Variable & Coefficient & Std. Error & t-Statistic & Prob. \\
\hline C & 1180.809 & 1536.865 & 0.768323 & 0.4492 \\
\hline IMT & 0.257016 & 0.115741 & 2.220608 & 0.0353 \\
\hline CT(-1) & 0.880683 & 0.092862 & 0.483744 & 30767.06 \\
\hline R-squared & 0.961406 & Mean dependent var & 26767.25 \\
\hline Adjusted R-squared & 0.958437 & S.D. dependent var & & $7.74 \mathrm{E}+08$ \\
\hline S.E. of regression & 5457.027 & Sum squared resid & & 1.700918 \\
\hline F-statistic & 330.0239 & Durbin-Watson stat & & \\
\hline Prob(F-statistic) & 0.000000 & & & \\
\hline
\end{tabular}

\section{Dependent Variable: CT;}

Method: Two-Stage Least Squares;

Date: 12/11/08, Time: 23:12;

Sample (adjusted): 1979 2007;

Included observations: 29 after adjustments;

Instrument list: C GT CT (-1) IT (-1).

Table 3.

\begin{tabular}{|c|c|c|c|c|}
\hline Variable & Coefficient & Std. Error & t-Statistic & Prob. \\
\hline C & 224.9145 & 762.8850 & 0.294821 & 0.7705 \\
\hline YT & -0.123501 & 0.049308 & -2.504709 & 0.0189 \\
\hline IT(-1) & 1.516373 & 0.109298 & 13.87372 & 0.0000 \\
\hline R-squared & 0.995235 & Mean dependent var & 27612.49 \\
\hline Adjusted R-squared & 0.994869 & S.D. dependent var & 34476.74 \\
\hline S.E. of regression & 2469.620 & Sum squared resid & & $1.59 \mathrm{E}+08$ \\
\hline F-statistic & 2715.744 & Durbin-Watson stat & & 0.778090 \\
\hline Prob(F-statistic) & 0.000000 & & & \\
\hline
\end{tabular}

Dependent Variable: IT;

Method: Two-Stage Least Squares;

Date: 12/11/08, Time: 23:22;

Sample (adjusted): 1979 2007;

Included observations: 29 after adjustments;

Instrument list: C GT CT(-1) IT(-1). 